Artikel Penelitian

\title{
Optimasi Parameter Permesinan Terhadap Tingkat Kekasaran Permukaan Aluminium Proses Pembubutan Dengan Metode Taguchi
}

\author{
Diki Ismail Permana ${ }^{a}$, Yayat $^{b}$ \\ ${ }^{a}$ Jurusan Teknik Mesin, Institut Teknologi Nasional, Jl. PHH Mustafa No.23 Bandung 40124, Indonesia \\ ${ }^{b}$ Jurusan Pendidikan Teknik Mesin, Universitas Pendidikan Indonesia, Jl. Setiabudhi No.299 Bandung, Indonesia
}

INFORMASI ARTIKEL

Sejarah Artikel:

Diterima Redaksi: 08 Februari 2019

Revisi Akhir: 22 Maret 2019

Diterbitkan Online: 29 April 2019

\section{KATA KUNCI}

Machining Parameteres

Surface roughness

Taguchi Method

KORESPONDENSI

E-mail: dicky91Permana@itenas.ac.id

\section{A B S T R A C T}

This study is aimed to determine the most suitable machining parameters to produce optimum surface roughness on turning operations using the Hurco TM20 CNC machine, ISCAR DNMG IC907 insert tool with aluminum 6061 as an object test material. The analysis was carried out using the Taguchi method with objective functions smaller the better and using ANOVA (analysis of variance) that determines which machining parameters have a significant effect on surface roughness. The machining parameters that evaluated are spindle speed, feedrate, and depth of cut. The test results shows that the machining parameters that produce the optimal surface roughness level is on range of $0.28 \pm 0.13$, and the parameters are spindle speed $=2092$ $\mathrm{rpm}$, feedrate $=0.07 \mathrm{~mm} / \mathrm{ref}$, dept of cut $=0.5 \mathrm{~mm}$.

\section{PENDAHULUAN}

Dalam industri manufaktur, proses produksi dilakukan dengan sangat cepat. Penggunaan mesin CNC sangat disarankan karena hasil proses yang dilakukan sangat baik dibandingkan dengan cara konvensional. Mesin CNC banyak dipakai di industri manufaktur diantaranya industri otomotif dan industri kedirgantaraan. Mesin CNC digunakan untuk membuat komponen - komponen otomotif, poros, cetakan blok mesin, cetakan ruang bakar, dan pekerjaan permesinan yang sifatnya meratakan permukaan, membuat lubang, ulir dan tap ulir.

Kualitas barang produksi dianggap baik apabila memenuhi kriteria atau memenuhi standar kualitas produk salah satunya pemenuhan dalam kualitas geometri [1]. Suatu komponen mesin mempunyai karakteristik geometri yang ideal apabila komponen tersebut mempunyai: 1) Ukuran/ dimensi produk yang presisi, 2) Bentuk produk yang sempurna, dan 3) Permukaan benda yang halus [1].

Seperti pada mesin produksi lainnya, saat melakukan proses pembubutan dengan mesin $\mathrm{CNC}$, seorang operator mesin perlu menentukan dan memilih parameter permesinan yang tepat agar mendapatkan hasil produk yang optimal. Parameter permesinan yang perlu ditentukan oleh seorang operator mesin bubut CNC yaitu kedalaman potong (depth of cut), kecepatan potong (cutting speed), kecepatan pemakanan (feed rate), dan putaran spindle (spindle speed). 
Pada proses pembubutan terdapat metode yang dipakai untuk menentukan suatu kualitas permukaan benda kerja salah satunya menggunakan Metode Taguchi. S.L Yim et al. [2] membahas berbagai metode analisa suatu proses permesinan agar dapat menghasilkan performans yang optimal.

Di antara metode eksperimen tersebut adalah : Metode desain uniform, metode desain faktorial fraksi, metode respon permukaan, metode grey analisis, dan metode taguchi. Menurut Yim [2], metode Taguchi merupakan metode design yang paling mudah dilakukan baik dari segi biaya maupun teknis pelaksanaanya. Metode Taguchi merupakan suatu metode yang cukup efektif dalam menentukan faktor yang berpengaruh terhadap suatu gejala atau proses tertentu.

Pada penelitian ini dipilih Metode Taguchi untuk menentukan parameter pemesinan yang terdiri dari kecepatan putaran spindel (spindle speed), kecepatan pemakanan (feed rate) dan kedalaman pemakanan (depth of cut) [3]. Alasan pemilihan parameter di atas adalah karena bisa dioptimasi oleh operator mesin CNC dengan cara melakukan kombinasi dari parameter-parameter tersebut.

\section{METODOLOGI}

Pada Gambar 1 diperlihatkan flow chart langkahlangkah dalam penelitian.

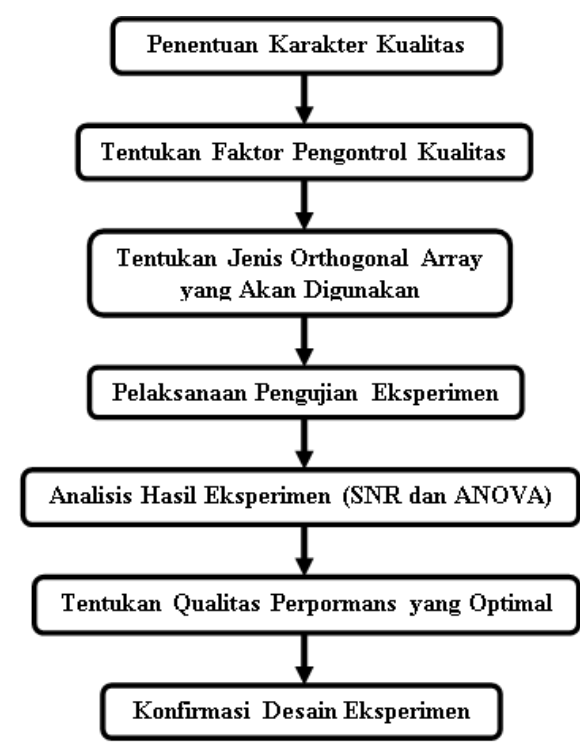

Gambar 1. Flow Chart Penelitian

\subsection{Penentuan Karakter Kualitas}

Terdapat tiga jenis karakter kualitas dalam metode eksperimen Taguchi, diantaranya adalah Smaller is better, Nominal the better, dan Larger the better [4]. Tujuan dari penelitian ini adalah untuk mendapatkan kekasaran permukaan (Ra) yang minimum pada proses pemesinan bubut. Kekasaran permukaan yang rendah menandakan kualitas permukaannya baik. Oleh karena itu, karakter kualitas yang dipilih adalah "Smaller is better".

\subsection{Penentuan Faktor Pengontrol Kualitas}

Dalam penelitian ini di pilih faktor atau parameter bebas diantaranya, kecepatan potong (cutting speed), kecepatan pemakanan (feed rate), kedalaman pemakanan (depth of cut). Untuk faktor kontrolnya adalah kekasaran permukaan, karena variabel ini hasilnya dipengaruhi oleh faktor bebas

Tabel 1. Desain Parameter dan Level Taguchi

\begin{tabular}{|c|c|c|c|c|}
\hline \multirow[b]{2}{*}{ Parameter } & \multicolumn{3}{|c|}{ Level } & \multirow{2}{*}{$\begin{array}{c}\text { Hasil } \\
\text { Penelitian }\end{array}$} \\
\hline & 1 & 2 & 3 & \\
\hline $\begin{array}{l}\text { Kec. Potong } \\
(\mathrm{m} / \mathrm{min})\end{array}$ & 152 & 167 & 183 & $\begin{array}{l}\text { - Kekasaran } \\
\text { permukaan }\end{array}$ \\
\hline $\begin{array}{l}\text { Kec. Spindel } \\
\text { (A) }(\mathrm{rpm})\end{array}$ & 1905 & 2093 & 2292 & \\
\hline $\begin{array}{l}\text { Kec. } \\
\text { Pemakanan (B) } \\
(\mathrm{mm} / \mathrm{ref})\end{array}$ & 0,05 & 0,07 & 0,10 & \\
\hline $\begin{array}{l}\text { Kedalaman } \\
\text { Pemakanan }(\mathrm{C}) \\
(\mathrm{mm})\end{array}$ & 0,5 & 1,0 & 1,5 & \\
\hline $\begin{array}{l}\text { Kondisi } \\
\text { Pemotongan }\end{array}$ & & Kerin & & \\
\hline
\end{tabular}

\subsection{Penentuan Jenis Orthogonal Array}

Ada empat parameter yang diteliti dalam eksperimen ini. Masing - masing parameter terdiri dari tiga level. Perhitungan derajat kebebasan berdasarkan jumlah faktor dan level dinyatakan oleh :

$$
\begin{aligned}
\text { Derajat kebebasan }= & (\text { banyaknya faktor }) \times \\
& (\text { banyaknya level }-1) \\
= & 3 \times(3-1)=6
\end{aligned}
$$

Matriks orthogonal harus dipilih sesuai dengan eksperimen. Dalam hal ini derajat kebebasan pada matriks orthogonal standar harus lebih besar atau 
sama dengan perhitungan pada eksperimen [4]. Dalam penelitian ini dipilih orthogonal array L9 seperti yang ditunjukkan pada Tabel 2 .

Tabel 2. Orthogonal Array

\begin{tabular}{|c|c|c|c|c|}
\hline \multirow{2}{*}{ Eksperimen } & \multicolumn{4}{|c|}{ Faktor } \\
\cline { 2 - 5 } & $\begin{array}{c}\text { Spindle } \\
\text { Speed } \\
\text { (A) }\end{array}$ & $\begin{array}{c}\text { Feedrate } \\
(\mathrm{B})\end{array}$ & $\begin{array}{c}\text { Depth } \\
\text { of Cut } \\
(\mathrm{C})\end{array}$ & $\begin{array}{c}\text { Cutting } \\
\text { Condition }\end{array}$ \\
\hline 1 & 1 & 1 & 1 & 1 \\
\hline 2 & 1 & 2 & 2 & 1 \\
\hline 3 & 1 & 3 & 3 & 1 \\
\hline 4 & 2 & 1 & 2 & 1 \\
\hline 5 & 2 & 2 & 3 & 1 \\
\hline 6 & 2 & 3 & 1 & 1 \\
\hline 7 & 3 & 1 & 3 & 1 \\
\hline 8 & 3 & 2 & 1 & 1 \\
\hline 9 & 3 & 3 & 2 & 1 \\
\hline
\end{tabular}

\subsection{Pelaksanaan Pengujian Eksperimen}

Ada sembilan set eksperimen dalam pengukuran tingkat kekasaran permukaan dengan parameter yang berbeda seperti terlihat pada Tabel 2. Mesin CNC yang digunakan dalam penelitian ini adalah Hurco TM6 dan pahat insert yang digunakan adalah Iscar DNMG IC907. Sedangkan, spesimen menggunakan Aluminium 6061 dan untuk pengukuran kekasaran permukaan spesimen menggunakan alat ukur surftest Mitutoyo SJ301 seperti diperlihatkan pada Gambar 2.

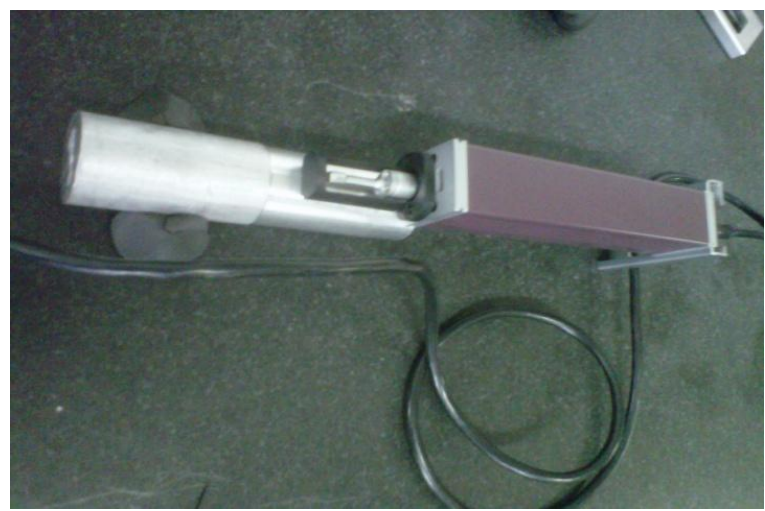

Gambar 2. Pengujian Tingkat Kekasaran

\subsection{Pengolahan Data}

Setelah data eksperimen terkumpul, maka dilakukan pengolahan data. Analisis hasil penelitian terdiri dari tiga macam, yaitu analisis hasil data rata-rata, $\mathrm{S} / \mathrm{N}$ Rasio dan analisis variansi (ANOVA).

\subsubsection{Analisis S/N Rasio}

Persamaan S/N Rasio diberikan oleh :

$\frac{s}{N}=-10 \log \left[\frac{1}{n} \sum_{i=n}^{n} y^{2}\right]$

Dimana $: n=$ jumlah pengukuran setiap pengujian $y=$ nilai data

S/N Rasio suatu ukuran untuk menentukan kualitas dari sebuah sinyal yang terganggu oleh derau atau bunyi [8]. Dalam penelitian ini, estimasi SNR dilakukan dengan menggunakan metode taguchi. Sinyal masukan (sinyal uji) dimodelkan dengan sinyal sinusoidal, karena dalam mengukur tingkat kekasaran yang hasilnya berupa grafik sinusoidal sangat tergantung oleh keadaan sekitar terutama bunyi.

\subsubsection{Analisis ANOVA}

Model Analisis Variansi merupakan teknik perhitungan kuantitatif yang memperkirakan kontribusi dari setiap faktor dalam mengidentifikasi pengujian kebeneran hipotesis terhadap pengaruh faktor terkendali [5]. Tujuan Anova adalah untuk menentukan parameter permesinan yang berpengaruh signifikan terhadap karakter kualias. Berikut beberapa persamaan yang digunakan dalam perhitungan Anova.

- Perhitungan Jumlah Kuadrat

$$
\mathrm{SS}=\left[\sum_{i=1}^{k A}\left(\frac{A i^{2}}{n_{A i}}\right)\right]-\frac{T^{2}}{N}
$$

- Perhitungan Derajat Kebebasan

$$
\mathrm{V}=\mathrm{N}-1
$$

- Perhitungan Rata-rata Kuadrat

$$
\mathrm{MS}=\frac{S S}{V}
$$

- Perhitungan Uji F-ratio

$$
\mathrm{F}=\frac{M S}{M S e}
$$

- Perhitungan SS'

$$
\mathrm{SS}^{\prime}=\mathrm{SS}-\mathrm{MSe}(\mathrm{V})
$$

- Perhitungan Persen Kontribusi 


$$
\mathrm{P}=\frac{S S I}{S S_{T}} \times 100 \%
$$

\section{HASIL DAN PEMBAHASAN}

\subsection{Analisis}

Parameter yang diolah dalam studi ini adalah data kekasaran rata-rata (Roughness Average) atau yang disingkat dengan $\mathrm{Ra}$. $\mathrm{Ra}$ merupakan harga aritmatik bagi harga absolut antara jarak profil terukur dengan profil tengah [3].

Analisis hasil untuk penelitian ini terdiri dari tiga macam yaitu analisis data rata-rata, analisis $\mathrm{S} / \mathrm{N}$ Rasio (SNR), dan analisis variansi (ANOVA). Tabel 3 merupakan hasil pengukuran tingkat kekasaran dan SNR setiap faktor.

Tabel 3. Hasil Pengukuran Tingkat Kekasaran

\begin{tabular}{|c|c|c|}
\hline Eksperimen & $\begin{array}{c}\text { Ra } \\
(\boldsymbol{\mu m})\end{array}$ & $\begin{array}{c}\text { SNR } \\
(\mathbf{d b})\end{array}$ \\
\hline 1 & 0.19 & 14.4 \\
\hline 2 & 0.27 & 11.4 \\
\hline 3 & 0.57 & 4.9 \\
\hline 4 & 0.23 & 12.8 \\
\hline 5 & 0.26 & 11.7 \\
\hline 6 & 0.49 & 6.2 \\
\hline 7 & 0.40 & 7.9 \\
\hline 8 & 0.24 & 12.4 \\
\hline 9 & 0.86 & 1.3 \\
\hline
\end{tabular}

\subsubsection{Pengaruh Level Faktor Terhadap Rata- rata Kekasaran Permukaan}

Untuk mengindentifikasi pengaruh level dari faktor terhadap rata-rata kekasaran permukaan, dilakukan pengolahan data respon kekasaran benda yang diperoleh dari pengukuran kekasaran. Sehingga di dapat grafik respon rata-rata kekasaran permukaan seperti yang ditunjukan oleh Gambar 3 .

Pada Gambar 3 dapat dilihat bahwa proses yang memberikan produk dengan performans terbaik adalah proses parameter yang memberikan nilai kekasaran minimum yaitu A2B2C1dengan nilai kekasaran berturut $\mathrm{A} 2=0.33 ; \mathrm{B} 2=0.26 ; \mathrm{C} 1=$ 0.31 .

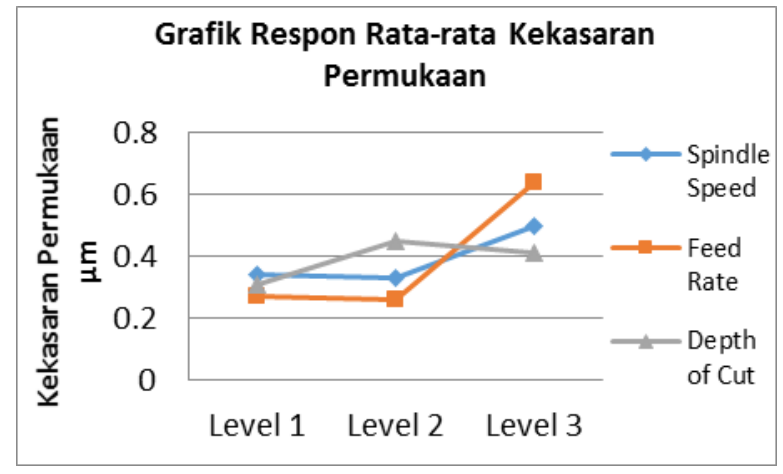

Gambar 3. Grafik Respon rata-rata Kekasaran Permukaan

\subsubsection{Pengaruh Level Faktor Terhadap $S / N$ Rasio}

Gambar 4 menunjukkan hubungan antara rasio S/N terhadap level dari cutting speed. Dari Gambar 4 dapat dikatakan bahwa parameter proses permesinan yang memberikan nilai SNR terbesar adalah A2B2C1 dengan nilai berturut-turut adalah $\mathrm{A} 2=10.2 ; \mathrm{B} 2=11.8 ; \mathrm{C} 1=11$, atau dengan kata lain parameter cutting speed berada pada level 2 yang menghasilkan nilai S/N Rasio sebesar 10,2 db ; feedrate pada level 2 menghasilkan $11,8 \mathrm{db}$; dan depth of cut pada level 1 menghasilkan $11 \mathrm{db}$.

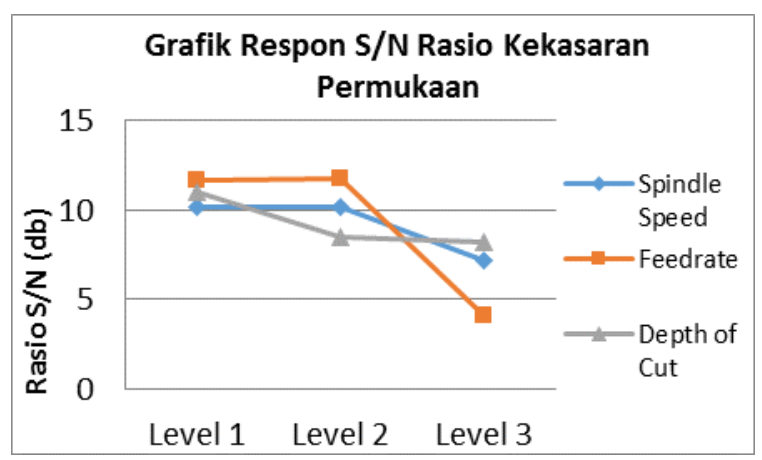

Gambar 4. Grafik Respon S/N Rasio Kekasaran Permukaan

\subsection{Anova}

Tujuan dari analisis variansi adalah untuk menentukan parameter permesinan yang signifikan terhadap karakteristik kualitas [5]. Analisis ANOVA diperlihatkan pada Tabel 4. Dari Tabel 4, terlihat bahwa hanya faktor B (feedrate) yang memberikan kontribusi terbesar terhadap rata-rata kekasaran permukaan benda kerja, yaitu sebesar 62,5\%. Sedangkan faktor C (Depth of Cut) hanya 
memberikan pengaruh terkecil terhadap kekasaran permukaan yaitu sebesar 2,5\%.

Tabel 4. Analisis Varians (ANOVA) untuk Rata-rata Kekasaran Permukaan

\begin{tabular}{|c|c|c|c|c|c|c|c|}
\hline Parameter & $\begin{array}{c}\text { Jumlah } \\
\text { Kuadrat }\end{array}$ & $\begin{array}{c}\text { Derajat } \\
\text { Kebebasan }\end{array}$ & $\begin{array}{c}\text { Rata-rata } \\
\text { Kuadrat }\end{array}$ & $\begin{array}{c}\text { F } \\
\text { hitung }\end{array}$ & $\begin{array}{c}\mathbf{F} \\
\text { Tabel }\end{array}$ & SS' & $\begin{array}{c}\text { Kontribusi } \\
(\%)\end{array}$ \\
\hline Spindle speed (A) & 0.05 & 2 & 0.025 & 1.67 & 4.46 & 0.02 & 5 \\
\hline Feed rate $(\mathrm{B})$ & 0.28 & 2 & 0.14 & 9.33 & 4.46 & 0.25 & 62.5 \\
\hline Depth of cut (C) & 0.04 & 2 & 0.02 & 1.33 & 4.46 & 0.01 & 2.5 \\
\hline Error & 0.03 & 2 & 0.015 & & & & 30 \\
\hline Total & 0.4 & 8 & & & & & 100 \\
\hline
\end{tabular}

Tabel 5. Analisis Varians (ANOVA) untuk S/N Rasio

\begin{tabular}{|l|c|c|c|c|c|c|c|}
\hline \multicolumn{1}{|c|}{ Parameter } & $\begin{array}{c}\text { Jumlah } \\
\text { Kuadrat }\end{array}$ & $\begin{array}{c}\text { Derajat } \\
\text { Kebebasan }\end{array}$ & $\begin{array}{c}\text { Rata-rata } \\
\text { Kuadrat }\end{array}$ & $\begin{array}{c}\mathbf{F} \\
\text { hitung }\end{array}$ & $\begin{array}{c}\text { F } \\
\text { tabel }\end{array}$ & SS' & $\begin{array}{c}\text { Kontribusi } \\
(\%)\end{array}$ \\
\hline Spindle speed (A) & 18.4 & 2 & 9.2 & 4.5 & 4.46 & 14.3 & 9.4 \\
\hline Feed rate (B) & 116.2 & 2 & 58.1 & 28.3 & 4.46 & 112.1 & 76 \\
\hline Depth of cut (C) & 14.2 & 2 & 7.1 & 3.5 & 4.46 & 10.1 & 6.6 \\
\hline Error & 4.1 & 2 & 2.05 & & & & 8 \\
\hline Total & 152.9 & 8 & \multicolumn{7}{|l}{} \\
\hline
\end{tabular}

Tabel 5 memperlihatkan analisis ANOVA untuk S/N Rasio. Berdasarkan Tabel 5, analisis variansi (ANOVA) untuk S/N Rasio dapat memperkuat pembahasan di atas tentang pengaruh parameter feedrate terhadap tingkat kekasaran permukaan. Hal ini dibuktikan dengan perhitungan kontribusi S/N Rasio pada parameter feedrate sebesar $76 \%$ dan perhitungan Fhitung (28.3) > Ftabel (4.46) [6].

\subsection{Prediksi Performan Optimal}

Telah diketahui faktor-faktor yang berpengaruh secara signifikan terhadap rata-rata kekasaran permukaan benda yang optimum, diantaranya :

Faktor Spindle Speed (A) level $2=2093$ Rpm

Faktor Feedrate (B) level $2=0,07 \mathrm{~mm} / \mathrm{ref}$

Faktor Depth of Cut $(\mathrm{C})$ level $1=0,5 \mathrm{~mm}$

Dengan menggunakan perhitungan prediksi kekasaran, di dapat nilai Ra prediksi minimum sebesar $0,15 \mu \mathrm{m}$ dan nilai maksimum sebesar 0,45 $\mu \mathrm{m}$, adapun nilai prediksi minimum untuk $\mathrm{S} / \mathrm{N}$ Rasio adalah 8,95 db dan maksimumnya sebesar $14,15 \mathrm{db}$.

\subsection{Konfirmasi Desain Eksperimen}

Dalam sistem parametrik desain, eksperimen konfirmasi sangatlah perlu dilakukan untuk mengecek apakah hasil analisis yang telah dilakukan benar atau tidak [7]. Eksperimen konfirmasi dilakukan berdasarkan hasil dari eksperimen sebelumnya. Pada eksperimen konfirmasi, faktor dan level ditetapkan seperti faktor dan level optimal yaitu faktor Spindle speed sebesar 2093 rpm yaitu pada level 2, kemudian faktor feedrate sebesar $0.07 \mathrm{~mm} / \mathrm{ref}$ yaitu pada level 2, dan faktor depth of cut sebesar $0.5 \mathrm{~mm}$ yaitu pada level 1. Untuk konfirmasi diambil 1 sampel dengan 3 pengukuran tingkat kekasaran dengan level pada kondisi optimum. 
Tabel 6. Konfirmasi Desain

\begin{tabular}{|c|c|c|c|c|}
\hline \multicolumn{3}{|c|}{$\begin{array}{c}\text { Tingkat Kekasaran Permukaan } \\
(\mathbf{R a})\end{array}$} & $\begin{array}{c}\text { Mean } \\
(\boldsymbol{\mu m})\end{array}$ & $\begin{array}{c}\text { S/N } \\
\text { Rasio } \\
(\mathbf{d b})\end{array}$ \\
\hline 1 & 2 & 3 & & 10,96 \\
\hline $0.27 \mu \mathrm{m}$ & $0.30 \mu \mathrm{m}$ & $0.28 \mu \mathrm{m}$ & 0.28 & 10 \\
\hline
\end{tabular}

Tabel 6 merupakan hasil dari eksperimen konfirmasi dengan menggunakan parameter prediksi optimum. Fungsi utama eksperimen konfirmasi ini adalah untuk memvalidasi dan memverifikasi apakah parameter permesinan yang telah ditunjukan oleh analisis sebelumnya benar atau tidak. Berdasarkan hasil analisis maka eksperimen konfirmasi dilakukan dengan memilih parameter proses yang optimal yaitu A2B2C1 dengan pengukuran kekasaran menghasilkan ratarata kekasaran permukaan sebesar $0.28 \mu \mathrm{m}$

\subsection{Pembahasan}

Berdasarkan hasil yang didapatkan pada analisis di atas, maka diketahui kombinasi faktor dan level yang berpengaruh terhadap rata-rata dan variansi tingkat kekasaran permukaan adalah relatif sama, Hal ini terbukti oleh faktor spindle speed pada level 2 sebesar $2093 \mathrm{rpm}$, faktor feedrate pada level 2 sebesar $0.07 \mathrm{~mm} / \mathrm{ref}$, dan faktor depth of cut pada level 1 sebesar $0.5 \mathrm{~mm}$, menghasilkan tingkat kekasaran permukaan rata-rata sebesar 0,28 $\mu \mathrm{m}$.

Dari hasil perhitungan interval kepercayaan pada tingkat kepercayaan 0.05 untuk eksperimen taguchi kemudian dibandingkan dengan interval kepercayaan untuk eksperimen konfirmasi berada pada interval kepercayaan eksperimen taguchi. Interval kepercayaan tersebut dapat dilihat pada Tabel 7.

Tabel 7. Hasil Eksperimen

\begin{tabular}{|c|c|c|c|}
\hline \multicolumn{2}{|c|}{$\begin{array}{l}\text { Respon } \\
\text { (Kekasaran Permukaan) }\end{array}$} & \multirow{2}{*}{$\begin{array}{l}\text { Prediksi } \\
0.30\end{array}$} & Optimasi \\
\hline \multirow{2}{*}{$\begin{array}{l}\text { Eksperimen } \\
\text { Taguchi }\end{array}$} & Rata-rata $(\mu \mathrm{m})$ & & $\begin{array}{l}0.30 \quad \pm \\
015\end{array}$ \\
\hline & $\mathrm{S} / \mathrm{N}$ rasio $(\mathrm{db})$ & 11.5 & $\begin{array}{l}11.5 \\
2.65\end{array}$ \\
\hline \multirow[t]{2}{*}{$\begin{array}{l}\text { Eksperimen } \\
\text { Konfirmasi }\end{array}$} & Rata-rata $(\mu \mathrm{m})$ & 0.28 & $\begin{array}{l}0.28 \\
0.13\end{array}$ \\
\hline & $\mathrm{S} / \mathrm{N}$ rasio $(\mathrm{db})$ & 10.96 & $\begin{array}{ll}10.96 \quad \pm \\
1.53\end{array}$ \\
\hline
\end{tabular}

Berdasarkan intreptasi hasil perhitungan tingkat kekasaran permukaan benda yang tertera pada Tabel 7, yaitu eksperimen Taguchi terhadap eksperimen konfirmasi mengalami peningkatan kualitas rata-rata dan mengalami penurunan pada variabilitasnya ( $\mathrm{S} / \mathrm{N}$ rasio), tetapi masih dalam range yang ditentukan. Dengan demikian, kombinasi optimal faktor-faktor tersebut di atas terbukti dapat meningkatkan kualitas kekasaran permukaan benda hasil produk proses pembubutan khususnya untuk benda uji berbahan aluminium 6061 .

\section{KESIMPULAN DAN SARAN}

Penelitian ini telah membahas aplikasi Metode Taguchi untuk menginvestigasi dan mempelajari pengaruh parameter permesinan terhadap kekasaran permukaan Aluminium 6061 dengan menggunakan mesin bubut CNC. Dari hasil analisis dapat disimpulkan bahwa :

1. Proses pembubutan yang akan memberikan hasil pembubutan dengan nilai kekasaran permukaan yang terbaik sesuai dengan rentang adalah proses permesinan dengan parameter $\mathrm{A} 2 \mathrm{~B} 2 \mathrm{C} 1$ yaitu pada spindle speed $=2093 \mathrm{rpm}$, feedrate $=0.07 \mathrm{~mm} / \mathrm{ref}$, dan depth of cut $=0.05 \mathrm{~mm}$.

2. Pada tingkat signifikan 5\% dari ketiga parameter tersebut yang memiliki pengaruh signifikan terhadap kekasaran permukaan adalah feedrate yang memberikan kontribusi sebesar 62.5\%, dibandingkan parameter lainya seperti spindle speed dan depth of cut yang hanya memberikan kontribusi berturut-turut $5 \%$ dan $2.5 \%$.

\section{DAFTAR PUSTAKA}

[1] Rochim,Taufiq, Spesifikasi, Metrologi dan Kontrol Kualitas Geometrik. Bandung, Indonesia: Penerbit ITB, 2001, Bandung. Pp. 979-9299-41-1

[2] S.L. Yim, K. M. Yu. Taguchi Methods to Optimize Tin Coating Surface Methods. Material Science Forum, 2004., Vols 471-472, pp 891-894. 
[3] Rochim, Taufiq. Teori dan Teknologi Proses Permesinan, Bandung, Indonesia: Penerbit ITB, 1982.

[4] Soejanto, Irwan. Desain Eksperimen Dengan Metode Taguchi. Yogyakarta, Indonesia: Graha Ilmu, 2009, pp. 978-979-756-492-6

[5] Sugiyono. Metode Penelitian Kuantitatif Kualitatif dan $R \& D$, Alfabeta, Bandung, Indonesia: Alfabeta, 2014, pp. 979-8433-64-0

[6] Siregar, S. Statistika Terapan. Jakarta, Indonesia : Grasindo, 2004, pp. 979-7329-739.

[7] Rusnaldi, et al. Optimasi Parameter Pemesinan Proses CNC Freis Terhadapa Hasil Kekasaran Permukaan Dan Keausan Pahat Menggunakan Metode Taguchi, Jurnal Teknik Mesin, Universitas Diponegoro, 2010

[8] Smith, Steven w. The Scientist and Engineer's Guide to Digital Signal Processing. USA : California Technical Publishing, 1999, 2nd edition, pp. 0-9660176-6-8 